\title{
Implementation of Thrust Ripple Reduction for a Permanent Magnet Linear Synchronous Motor Using an Adaptive Feed Forward Controller
}

\author{
Arundhati Baratam ${ }^{\dagger}$, Alice Mary Karlapudy ${ }^{*}$, and Suryakalavathi Munagala** \\ $\dagger^{*}$ Dept. of Electrical \& Electronic Eng., Vignan Institute of Information Technology, Visakhapatnam, India \\ ${ }^{* *}$ Dept. of Electrical \& Electronic Eng., Jawaharlal Nehru Technological University, Hyderabad, India
}

\begin{abstract}
This paper focuses on the analysis and compensation of thrust ripples in permanent magnet linear synchronous motors (PMLSM). The main drawback in PMLSMs is the presence of thrust ripples, which are mainly due to the interaction between the permanent magnets and armature slotted core. These thrust ripples reduce the performance of the drive system in high precision applications especially at low speeds. This paper analyzes thrust ripples using the discrete wavelet transform. These undesired thrust ripples are compensated by using an adaptive feed forward controller. It is observed that this novel controller reduces about 65 percent of the thrust ripples. An extensive simulation is performed through MATLAB and it is validated through experimental results using a d-SPACE system with a DS1104 control board.
\end{abstract}

Key words: Adaptive feed forward controller, Detent thrust ripples, Discrete wavelet transform, DS1 104 control board, d-SPACE, Permanent Magnet Linear Synchronous Motor (PMLSM)

\section{INTRODUCTION}

In today's highly competitive manufacturing environment, a lot of resources are being dedicated to developing a simple, efficient and optimal solutions for process automation and material handling processes. These days permanent magnet direct drive motors are becoming more and more popular in machine automation. The major advantages of permanent magnet linear motor drives are their gearless structure, excellent control characteristics such as high speed and acceleration and high motion precision, and better efficiency. PMLSM possess an important drawback in terms of thrust ripples due to the detent force which is mainly caused by the interaction between the permanent magnets and the armature slotted core and end effect [1]. In general, the end component

Manuscript received Oct. 9, 2013; accepted Mar. 1, 2014

Recommended for publication by Associate Editor Dong-Hee Lee.

Corresponding Author: b arundhati@rediffmail.com

Tel: +202-33310512, Fax: +202-33351631, VIT

*Dept. of Electrical \& Electronic Eng., VIIT, India

${ }^{* *}$ Dept. of Electrical \& Electronic Eng., JNUC, India of a machine is larger than the slot component [2], [3]. The detent force is most sensitive to mover tooth width and stator tooth width variations. The detent force can be reduced to a great extent by optimizing the individual parameters of the motor and through global optimization using a genetic algorithm [4].

The detent force is the major component of the thrust ripples which deteriorates the control characteristics of PMLSM at low speeds. The effects of the thrust ripple are particularly undesirable in some demanding motion control and machine tool applications. They lead to speed oscillations, which result in a deterioration in performance. The thrust ripples change periodically as the mover advances during its motion. The thrust ripples can be reduced by either machine designs [5], [6] or control methods [7], [8]. There are several methods traditionally used to minimize the tooth type detent force. These include skewing the magnets [9], shaping the magnets [10], and/or skewing the slots in the laminations. The effectiveness of skewing depends largely on the axial variation of the thrust ripple phase but less on its magnitude, and the no load torque ripple cannot be fully eliminated by skewing [11]. 
All of these methods reduce cogging by intentionally misaligning the laminations teeth from one magnet to the next. However, this also reduces the motor's thrust output and efficiency. Due to the direct drive nature of linear motors, there are no intermediate mechanical components or gear reductions to absorb external disturbances. As a result, the disturbances due to thrust ripples have a greater impact in PMLSMs. To obtain accurate tracking in high performance position control systems, it is necessary to have a controller to compensate the nonlinear force disturbance caused by detent and frictional forces.

The basic goal of this paper is to control current so that the thrust ripple is cancelled out. The thrust ripples are measured experimentally. It is observed that the thrust ripple due to detent thrust, exhibits a periodic relationship with respect to the position of the mover. By using a discrete wavelet filter the output waveform is smoothened. The detent thrust is compensated by using the adaptive feed forward thrust compensator corresponding to the position of the mover.

\section{DYNAMIC MODEL OF PMLSM}

The mathematical analysis of a Permanent Magnet Linear Synchronous Motor (PMLSM) is a key factor in the development of a motor control system.

The $d-q$ voltage equations of a PMLSM in the synchronous rotating frame are [12]:

$$
\begin{gathered}
v_{d s}=R_{s} i_{d s}+L_{d} \frac{d i_{d s}}{d t}-\frac{\pi}{\tau} v_{r} L_{q} i_{q s} \\
v_{q s}=R_{s} i_{q s}+L_{q} \frac{d i_{q s}}{d t}+\frac{\pi}{\tau} v_{r} L_{d} i_{d s}+\frac{\pi}{\tau} v_{r} \psi_{p m}
\end{gathered}
$$

where $v_{d s}$ and $v_{q s}$ are the terminal voltage, $i_{d s}$ and $i_{q s}$ are the armature currents, and $L_{d}$ and $L_{q}$ are the $\mathrm{d}$ and q-axis components of the resultant armature inductance. $\psi_{p m}$ is the flux linkage of the permanent magnet per phase.

The synchronous speed of PMLSM is:

$$
\omega_{r}=\frac{\pi v_{r}}{\tau}
$$

where $\tau$ is the pole pitch, and $v_{r}$ is the linear synchronous velocity.

The electromagnetic thrust of a PMLSM with p pole pairs is:

$$
F_{e}=\frac{3}{2} p \frac{\pi}{\tau}\left[\psi_{p m} i_{q s}-\left(L_{q}-L_{d}\right) i_{d s} i_{q s}\right]
$$

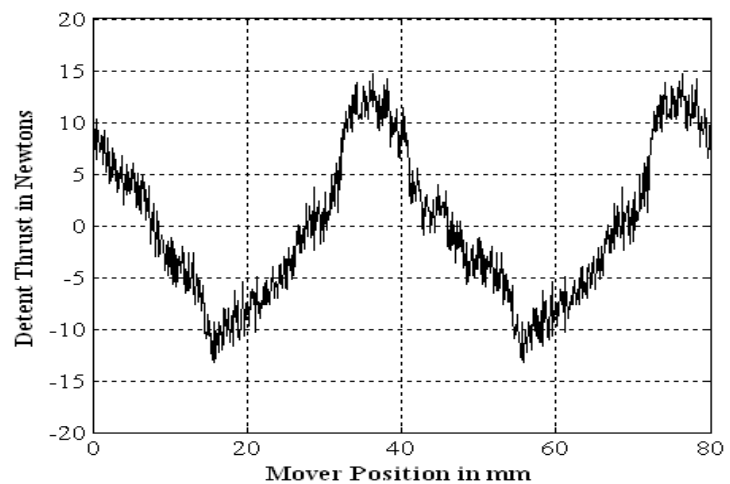

Fig.1. Detent thrust versus position of PMLSM.

The mechanical thrust equation considering the detent thrust is represented as [13]:

$$
F_{e}-F_{d}(x)=M \frac{d v_{r}}{d t}+B v_{r}+F_{l}+F_{r}
$$

where $\mathrm{M}$ is the total mass of the mover, $\mathrm{B}$ is the damping coefficient, $v_{r}$ is the mover mechanical velocity, $F_{d}$ is the detent force which is a function of the mover position $(x), F_{1}$ is the external load thrust, and $\mathrm{F}_{\mathrm{r}}$ is the frictional thrust.

\section{ANALYSIS OF DETENT THRUST}

The thrust ripples in a PMLSM are due to the detent thrust. There are two major causes of the detent thrust. One is due to the attractive force between the armature core and the permanent magnet in the thrust-direction called the slot component. The other one is due to the finite length of the iron-cored armature called the end component. This detent thrust is independent of the primary current. Unfortunately, the detent thrust is quite difficult to model accurately.

\section{A. Measurement of Detent Thrust}

The detent thrust is measured by moving the motor at a constant velocity and recording the current output of the driving amplifier versus time. Knowing the velocity and the motor's thrust constant, the thrust versus position can be obtained by moving the motor at $200 \mathrm{~mm} / \mathrm{s}$. This motor has a magnetic pitch of $40 \mathrm{~mm}$ which leads to the periodic waveform shown in the Fig. 1. The thrust plot is smoothened by using the wavelet transform.

\section{B. Wavelet-based Smoothing}

The measured value of the detent thrust is corrupted by noise during acquisition. Smoothening is used to remove the additive noise while retaining, as much as possible, the import signal characteristics, regardless of the frequency content [14]. The wavelet-based methods rely mainly on thresholding the 


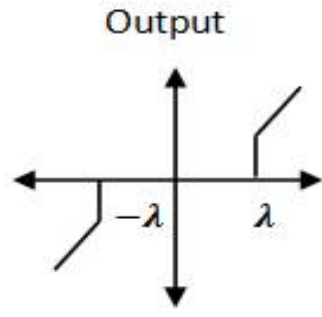

(a)

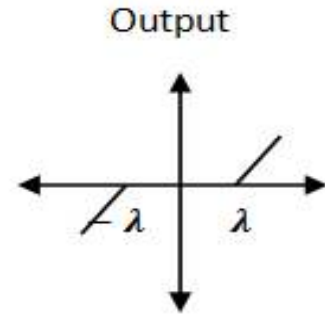

(b)
Fig. 2. (a) Hard thresholding. (b) Soft thresholding function.

Discrete Wavelet Transform (DWT) coefficients which have been affected by additive Gaussian noise. Thresholding is a simple non-linear technique which operates on one wavelet coefficient at a time. If the coefficient is smaller than the threshold, it is set to zero, otherwise the coefficient is kept as it is. Generally, smoothing removes high frequency components and retains low frequency components. Restoration is a kind of de-noising that tries to retrieve the original signal. Traditional smoothing filters such as mean, median and Gaussian filters are linear operators that are normally employed in the spatial domain wavelet. Wavelet-based de-noising is widely popular due to properties such as a multi resolution structure. Wavelet-based de-noising methods mostly employ nonlinear thresholding of the wavelet coefficients and image reconstruction.The standard thresholding of wavelet coefficients is governed mainly by either 'hard' or 'soft' thresholding functions, as illustrated in Fig. 2. In hard thresholding, the wavelet coefficients below the threshold $\lambda$ are made zero and the coefficients above this threshold are not changed. If $(\mathrm{x}, \mathrm{y})$ denote the input and the output then hard threshold $\mathrm{T}_{\mathrm{h}}(\mathrm{y}, \lambda)$ is given by:

$$
\begin{array}{r}
\hat{\chi}=\mathrm{T}_{h}(\mathrm{Y}, \lambda) \quad\{\mathrm{y}, \text { if } \mathrm{y} \geq \lambda \\
\{0, \text { if } \mathrm{y}<\lambda
\end{array}
$$

In soft thresholding it is given by:

$$
\hat{\chi}=\mathrm{T}_{s}(\mathrm{Y}, \lambda) \quad\left\{\begin{array}{l}
\mathrm{y}-\lambda, \text { if } \mathrm{y} \geq \lambda \\
\mathrm{y}+\lambda, \text { if } \mathrm{y} \leq-\lambda
\end{array}\right.
$$

In soft thresholding, the wavelet coefficients converge towards zero by the offset $\lambda$. Generally, soft thresholding generates fewer coefficients and preserves smoothness. The threshold choice plays a crucial role here.The universal threshold proposed by Donoho and John stone [15] is as follows:

$$
\lambda_{\min }^{2}=2 * \ln (m) * \sigma_{w}^{2}
$$

where $m$ is the signal size, and $\sigma_{\omega}^{2}$ is the noise variance.

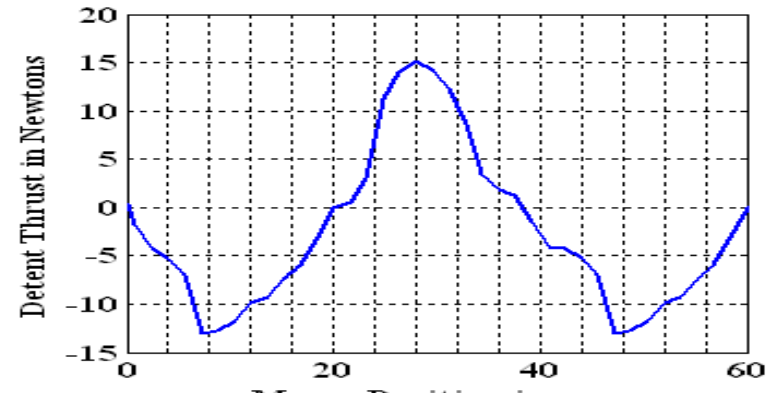

Mover Position in mm

Fig. 3. Measured Detent thrust verses mover position after smoothening.

\section{Analysis of the Detent Thrust Using Wavelet-Based Smoothing}

The detent thrust is prominent at low speeds under the no load condition of high performance PMLSM drives. Therefore, the detent thrust is investigated at $20 \mathrm{~mm} / \mathrm{s}$ and under the no load condition. Here, a 4-level asymmetric dyadic filter bank of 4-element Daubechies coefficient is used for smoothing the measured detent thrust. Since noise variance $\sigma^{2}{ }_{\omega}$ is not known, for various values of $\sigma^{2}{ }_{\omega}$, the results are determined, and the value of $\sigma^{2}{ }_{\omega}$ for which the smoothness is best, is finally chosen. The detent thrust verses mover position after smoothening is shown in fig 3 .

\section{CONTROL SYSTEM DESIGN}

The main goal of the control algorithm in this paper is to control the current so that the thrust ripple is cancelled out. Thrust variations of very low frequency are normally eliminated by the speed control system. Thrust ripples of higher frequencies can be compensated by generating an inverse thrust component through appropriate modulation of the mover current. When the field oriented control method is used, the modulation of the mover current is function of the amplitude of the q-axis current component $i_{q}$. In this paper, the proposed adaptive speed controller represented in the conventional two-loop structure for a motor drive is shown in Fig. 4.

The outer loop is the speed controller. The feedback speed $\mathrm{V}_{\mathrm{r}}$ is compared with the reference speed value $\mathrm{V}_{\mathrm{e}}{ }^{*}$, and the PI controller adjusts the error between $\mathrm{V}_{\mathrm{e}}{ }^{*}$ and $\mathrm{V}_{\mathrm{r}}$ to zero. The output of the PI controller is the thrust $F_{\mathrm{e}}$. Using the field orientation control reference values of the currents, iq is computed making $i_{d}=0$. The outer loop does not consider the ripples in the thrust. For high precision and accurate control, it is necessary to analyze and give an appropriate function of the detent thrust, and then compensate these thrust ripples. The compensating current $i_{\mathrm{qc}}$ is obtained from the thrust ripple 


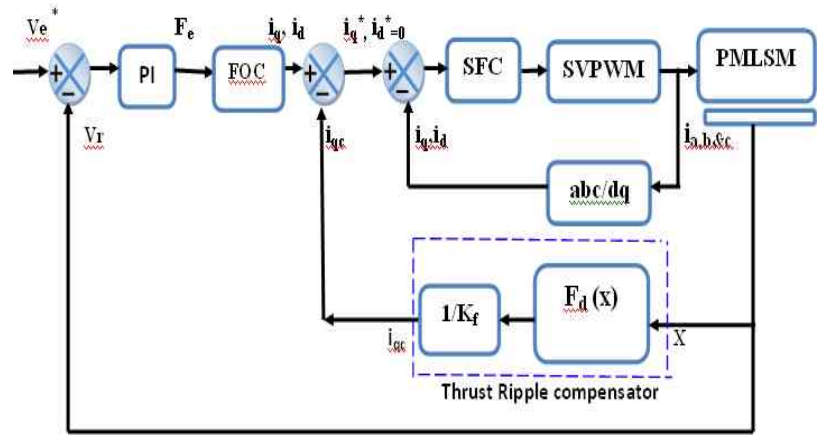

Fig. 4. Proposed control block diagram of PMLSM.

compensator block corresponding to the position of the motor. It is then added to the current $i_{q}$ to obtain the reference current $\mathrm{i}_{\mathrm{q}}$ * The inner loop is the current controller which consists of a nonlinear controller by which the system's nonlinearity is canceled. In addition, a linear state feedback control law based on the pole placement technique where the integral of output error (IOE) is used. The output of the current controller determines the time duration of the switching vectors $T_{1}$ and $\mathrm{T}_{2}$ of the space vector based PWM voltage source inverter.

\section{A. Design of the Outer Loop PI Controller}

The output of the PI controller is the reference thrust $F_{e}^{*}$, from which the currents, $i_{q}$ and $i_{d}^{*}$, for the mover winding are generated. The PI Controller coefficients $\mathrm{K}_{\mathrm{p}}$ and $\mathrm{K}_{\mathrm{i}}$ are as follows:

$$
\begin{gathered}
K_{p}=2 \varepsilon \omega_{n} \mathrm{M}-\mathrm{B} \\
K_{i}=\omega_{n}^{2} \mathrm{M}
\end{gathered}
$$

where, $\varepsilon$ is the desired value of the damping ratio, and $\omega_{n}$ is the desired value of the natural frequency.

\section{B. Reference current generator}

Reference current is obtained using Field Orientation Control (FOC) by setting the power factor angle to be equal to the torque angle, which results in complete decoupling between the armature flux and the field flux.

In FOC, since the d-axis current $i_{d}^{*}=0$, the electrical thrust is:

$$
F_{e}=\frac{3}{2} p \frac{\pi}{\tau} \psi_{p m} i_{q}=K_{f} i_{q}
$$

The thrust is a function of the q axis current $i_{q}$. The reference current is:

$$
i_{q}=\frac{F_{e}}{K_{f}}
$$

where, $K_{f}$ is the thrust constant in N/A.

$$
K_{f}=\frac{3}{2} p \frac{\pi}{\tau} \psi_{p m}
$$

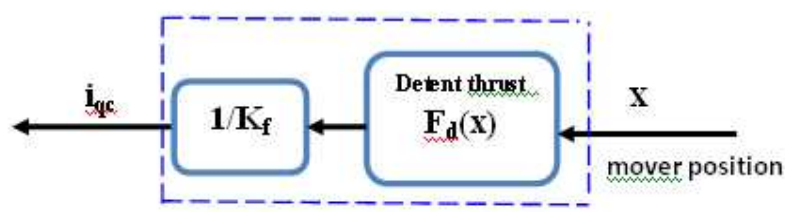

Fig. 5. Thrust Ripple compensator Block.

\section{Detent Thrust Compensator}

The thrust ripple compensation block is shown in the dashed region of proposed control block diagram in Fig.4. The detent thrust $F_{d}$ is a position dependent function. A lookup table is used to determine the detent thrust online depending on the position of the mover as derived in Fig. 3. The q-axis

compensating current corresponding to the detent thrust extracted by wavelet analysis is obtained as shown in Fig. 5.

$$
i_{q c}=\frac{F_{d}(x)}{K_{f}}
$$

The thrust ripple compensation block gives a predictive compensating q-axis current $\mathrm{i}_{\mathrm{qc}}$ to cancel out the thrust ripples at every instant of the mover position (x) .

\section{Space Vector Modulation}

The Space Vector Modulation (SVM) method is the most advanced, computation intensive PWM method. It is also the best among all of the PWM techniques for controlling high dynamic performance machine drives. At low speeds the SVM method with zero voltage vectors at the beginning, middle and end of the carrier cycle minimizes the current ripple and hence the thrust ripple.

The d-axis and q-axis control voltage from the PMLSM controller gives the magnitude of the voltage phasor, its angle and the sector in which the phasor resides at that instant. The time duration of the switching vectors $T_{1}$ and $T_{2}$ is calculated for $\mathrm{n}$ sectors as follows:

$$
\begin{gathered}
T_{1}=T_{s} * a * \sin \left(\frac{n \pi}{3}-\alpha\right) \\
T_{2}=T_{s} * a * \sin \left(\alpha-\frac{(n-1) \pi}{3}\right) ; n=1,2,3 \ldots 6
\end{gathered}
$$

Where, $a=\frac{2}{\sqrt{3}} * \frac{V^{*}}{V_{1}}=\frac{2}{\sqrt{3}} * \frac{V^{*}}{V_{2}}, \mathrm{~T}_{\mathrm{s}}=$ the sampling time, $\mathrm{T}_{1}$, $\mathrm{T}_{2}$ and $\mathrm{T}_{0}$ are the durations for which $\mathrm{V}_{1}, \mathrm{~V}_{2}$ and $\mathrm{V}_{0}$ or $\mathrm{V}_{7}$ are applied, $\alpha$ is the angle of $\mathrm{V}^{*}$ with the $\mathrm{d}$-axis, and $\mathrm{n}$ is the sector number. One of the important advantages of the SVPWM over the SPWM is that it produces nearly $15 \%$ more output voltage. 


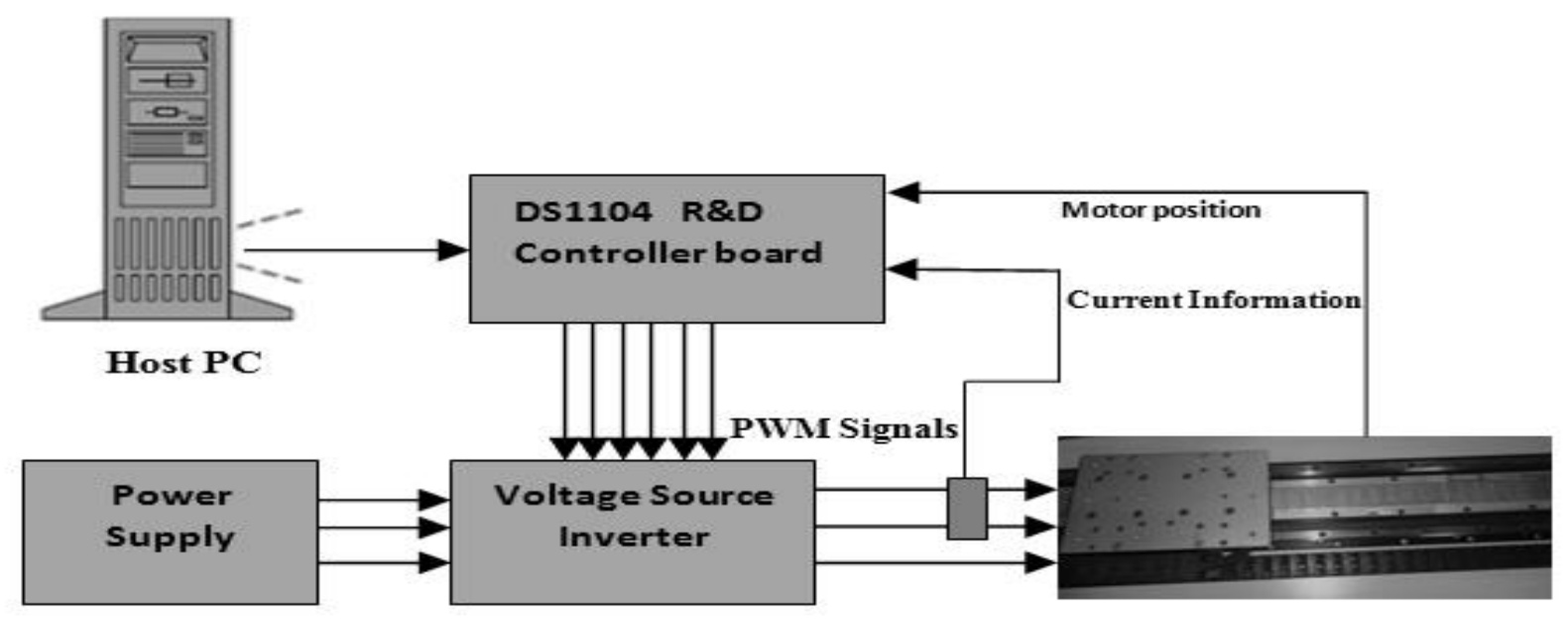

Fig. 6. Real time control of PMLSM Hardware layout.

\section{EXPERIMENTAL SETUP}

To implement the proposed control scheme, an experimental test was carried out. It is composed of:

- A PMLSM with a rated thrust of $154 \mathrm{~N}$

- A static power electronics converter comprised of a diode rectifier and a three-leg voltage source IGBT inverter.

- Linear incremental encoder (magnetic type)

- $\quad$ Hall effect current sensors Model LTS 6.

- A dSPACE DS1104 control board

The proposed adaptive controller algorithm is programmed using MATLAB/Simulink and downloaded into a dSPACE DS-1104 control board which is equipped with a TMS320C240 16-bit DSP processor. The DSP acts as a slave processor and provides the necessary digital input/output (I/O) ports and powerful timer functions such as input capture, output capture, and pulse width modulation (PWM) waveform generation. The output control signals of the slave I/O PWM are of TTL level $5 \mathrm{~V}$.

The power circuit for the drive consists of an IGBT based voltage source inverter with an opto-isolation and gate driver circuit. A sampling period of $100 \mu$ s is selected and the IGBTs are switched at a frequency of $10 \mathrm{kHz}$ with a dead time of $20 \mu \mathrm{s}$. The actual motor currents are measured by LEM Hall-effect sensors (model LTS6), which have a good frequency response and are fed to the dSPACE board through the A/D converter. The mover speed and position are measured by a magnetic linear incremental encoder. They are then fed to the dSPACE board through an encoder interface. The encoder generates the pulses per revolution. A 24-bit position counter is used to count the encoder pulses and it is read by a calling function in the software. The motor speed is calculated from the mover position by backward difference interpolation.

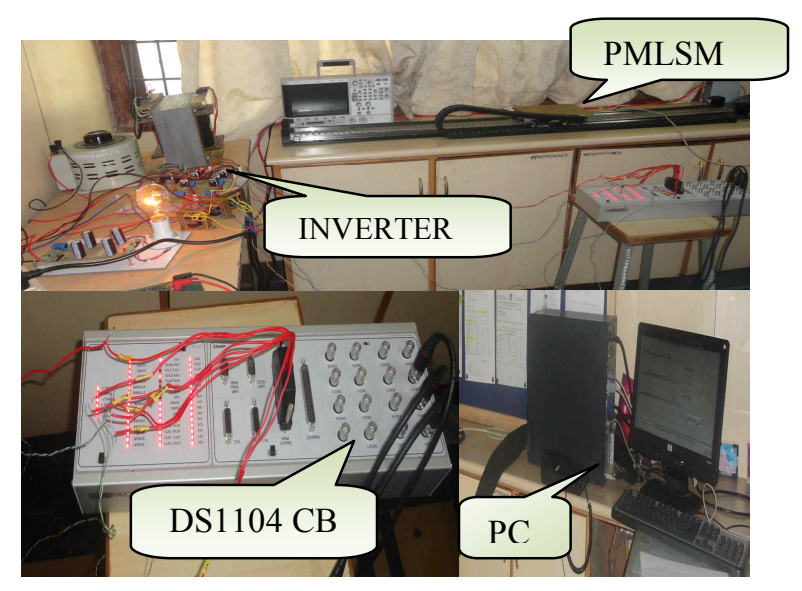

Fig. 7. Experimental setup of PMLSM.

\section{SIMULATION AND EXPERIMENTAL RESULTS}

In order to check the validity of the implementation of the adaptive observer based controller for PMLSM drives using dSPACE DS-1104 control board some simulation and experimental works have been performed on a PMLSM with the specifications shown in the appendix.

\section{A. Simulation Results}

The performance of the control strategy under the no load condition both without and with compensation of the detent thrust is observed. Fig. 8 shows the reference current $\mathrm{i}_{\mathrm{q}}{ }_{\mathrm{q}}$, at 2 sec (point of compensation). It can be seen that the reference current is increased which in turn counteracts the detent force ripples caused by the PMLSM. Fig. 9 and Fig. 10 show the simulation results while Fig. 14 and Fig. 15 show the 

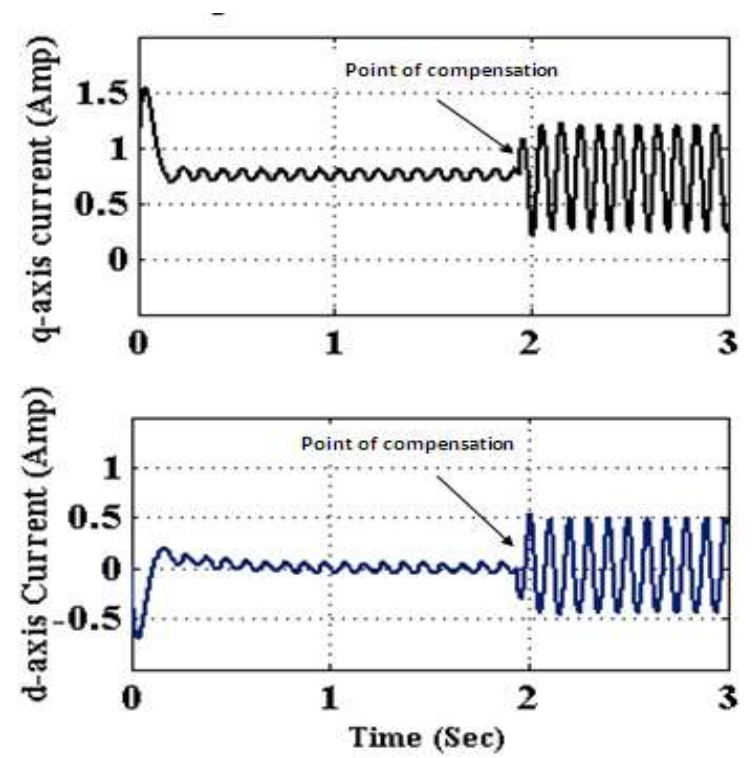

Fig. 8. $\mathrm{q}-\mathrm{d}$ axis motor current with detent thrust compensation at time 2 secs .

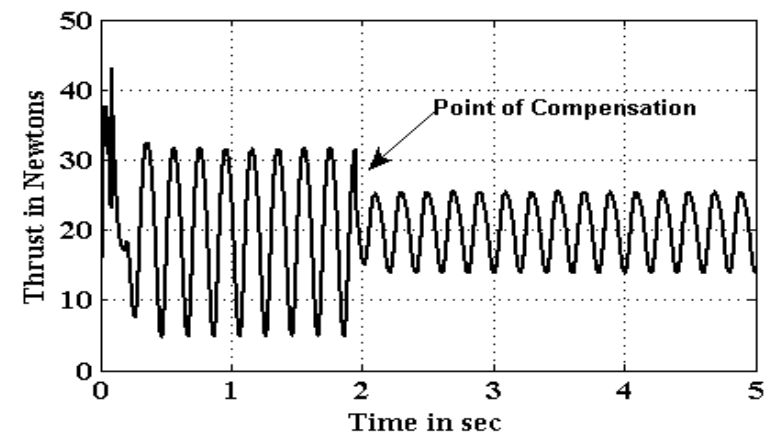

Fig. 9. Simulation results of Motor thrust at no load \& frictional thrust of $20 \mathrm{~N}$ with detent thrust compensation at time $2 \mathrm{sec}$.

experimental results of the motor speed at $0.2 \mathrm{~m} / \mathrm{sec}$ and the thrust with detent thrust compensation at $2 \mathrm{sec}$. Fig. 16 shows the motor thrust without compensation.

\section{B. Experimental Results}

The DS1104 Controller Board is designed for the development of high-speed multivariable digital controllers and real-time simulations. It is a real-time control system based on the Power PC604e processor. For advanced I/O purposes, the board includes a slave-DSP subsystem based on the Texas Instruments TMS320F240 DSP microcontroller. For the purpose of Rapid Control Prototyping (RCP), specific interface connectors and connector panels provide easy access to all of the input and output signals of the board. Fig 11 shows the current sensor interface \& Fig. 12 shows the encoder interface to DS1104 control board. The control structure is programmed in the Simulink graphical model and implemented by Real-Time Interface (RTI) on the DS1104 Controller Board.

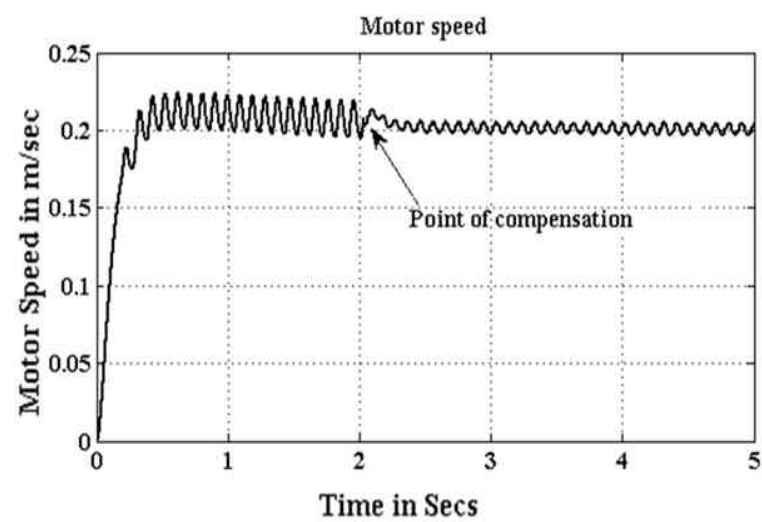

Fig. 10. Simulation results of motor for a set speed of $0.2 \mathrm{~m} / \mathrm{s}$ with detent thrust compensation at time $2 \mathrm{sec}$.

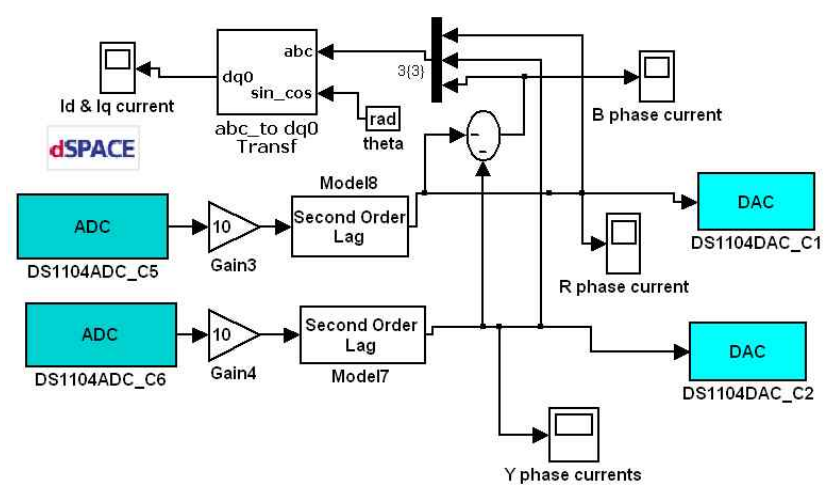

Fig. 11. Current sensor Interface to DS1104 control board.

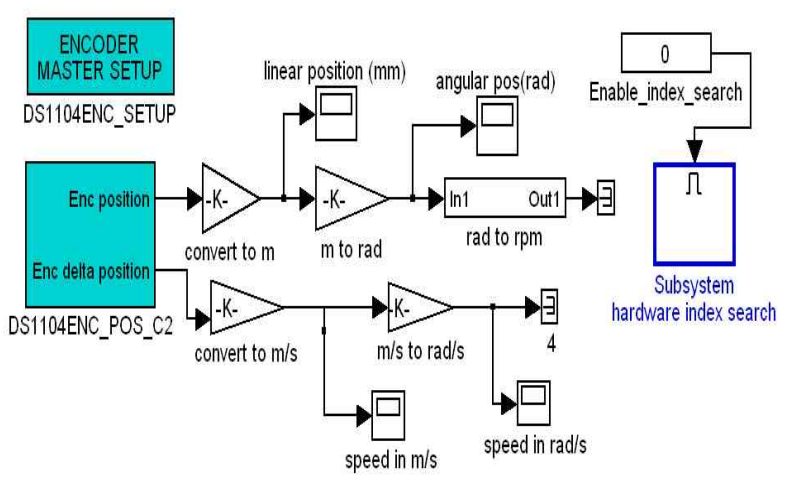

Fig. 12. Encoder Interface to DS1104 control board.

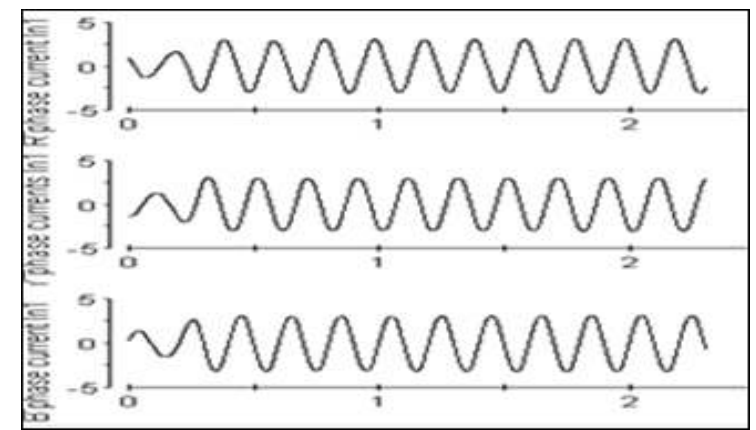

Fig. 13. Phase current waveform at motor speed $0.2 \mathrm{~m} / \mathrm{sec}$. 


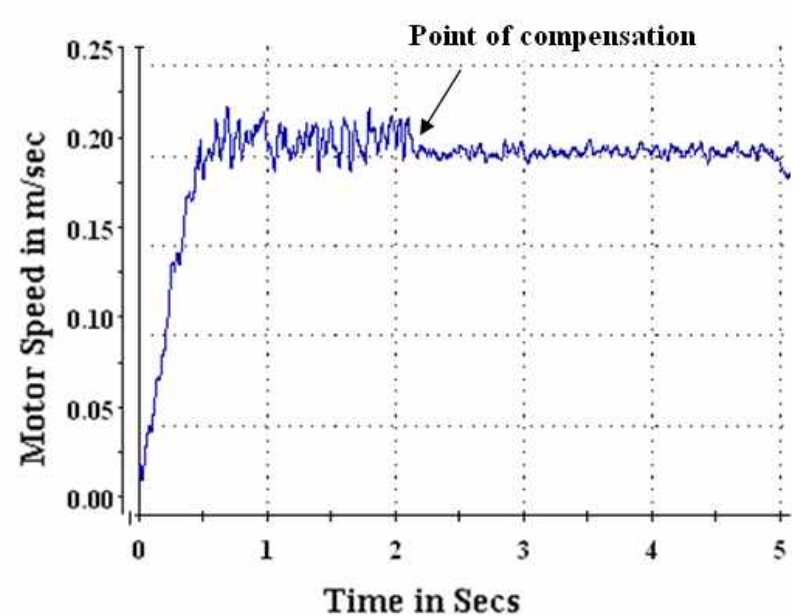

Fig. 14. Experimental results of motor for a set speed of $0.2 \mathrm{~m} / \mathrm{s}$ at no load with detent thrust compensation at time 2 secs.

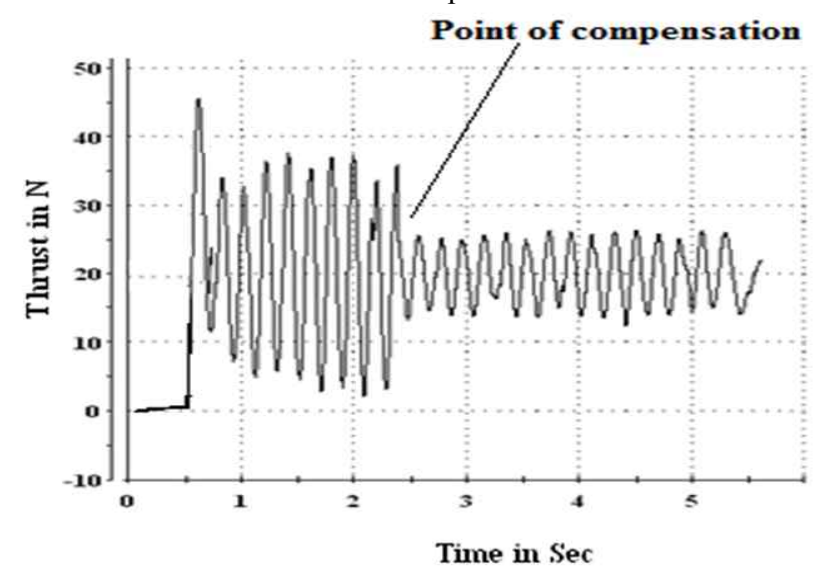

Fig. 15. Experimental results of motor thrust at no load \& frictional force of $20 \mathrm{~N}$ with detent thrust compensation after 2 secs.

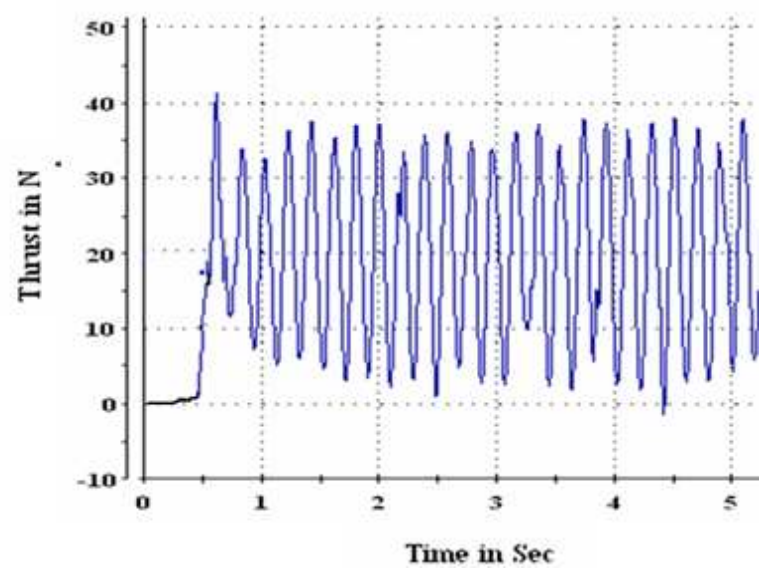

Fig. 16. Experimental results of motor thrust without detent thrust compensation.

The PMLSM control is implemented in three tasks containing the $\mathrm{I} / \mathrm{O}$ and two control layers. The measure task is directly triggered by the PWM interrupt of the TMS320F240. This closely connects the task cycles of the TMS320F240 and the PowerPC 603e to avoid jitters. It works at a PWM frequency of $10 \mathrm{kHz}$.

\section{CONCLUSIONS}

This paper introduces a simple method to reduce the thrust ripples in permanent magnet linear synchronous motors. The thrust ripple of the PMLSM is measured experimentally. Then it is analyzed using wavelet filters. The thrust ripple exhibits a periodic relationship with respect to the position of the mover relative to the stator magnets. It is observed that by using the adaptive feed forward detent thrust current compensator the thrust ripple of the PMLSM is reduced 65\%. Without compensation the peak to peak value of the detent thrust was $28 \mathrm{~N}$ and after compensation it was reduced to $10 \mathrm{~N}$. From the simulation and experiment outputs it can be concluded that the effect of the detent thrust is minimized drastically by using the proposed adaptive controller.

\section{APPENDIX}

Specifications Of the PMLSM

Rated thrust $=154 \mathrm{~N}$

Nominal power $=3910 \mathrm{~W}$

Rated current $=4.67 \mathrm{~A}$

Rated speed $=4.5 \mathrm{~m} / \mathrm{s}$

Resistance/phase $=2.1 \Omega$

Inductance $/$ phase $=3.05 \mathrm{mH}$

Mass of the mover $=4.5 \mathrm{Kg}$

Thrust constant $=32.7 \mathrm{~N} / \mathrm{A}$

Magnetic pole pitch $=40 \mathrm{~mm}$

Back emf constant $=27 \mathrm{~V} / \mathrm{m} / \mathrm{s}$

\section{ACKNOWLEDGMENT}

This work is supported by All India Council of Technical Education (AICTE), New Delhi under Research Promotion Scheme, File No 8023/RID/RPS-78/2011.

\section{REFERENCES}

[1] K. Bao-quan, W. Hong-Xing, L. Li-yi, Z. Liang-Liang, Z. Zhe, and C. Hai-Chuan, "The thrust characteristics investigation of double side plate permanent magnet linear synchronous motor for EML," IEEE Trans. Magn., Vol. 45, No. 1, pp. 501-505, Jan. 2009

[2] Y. J. Kim, M. Watada, and H. Dohmeki, "Reduction of the cogging force at the outlet edge of a stationary segment primary linear synchronous motor," IEEE Trans. Magn., Vol. 43, No. 1, pp. 40-45, Jan. 2007.

[3] X. Shangguan, S. Yuan, and Q. F. Li "Study on cogging force of permanent magnet linear synchronous motor," Journal of Coal Science and Engineering, Vol. 11, pp. 89-92, 
Jun. 2005.

[4] A. Gandhi and L. Parsa, "Thrust optimization of a Flux-switching Linear Synchronous Machine with yoke less

translator," IEEE Trans. Magn., Vol. 49, No. 4, pp. 1436-1443, Apr. 2013.

[5] P. J. Hor, Z. Q. Zhu, D. Howe, and J. Rees-Jones, "Minimization of cogging force in a linear permanent magnet motor," IEEE Trans. Magn., Vol. 34, No. 5, pp. 3544-3547, Sep. 1998.

[6] Y. Pang, Z. Q. Zhu, and Z. J. Feng, "Cogging torque in cost effective surface mounted permanent magnet machines," IEEE Trans. Magn., Vol. 47, No. 9, pp. 2269-2276, Sep. 2011.

[7] J. X. Xu, S. K. Panda, Y. J. Pan, T. H. Lee, and B. H. Lam, "A modular control scheme for PMSM speed control with pulsaing torque minimization," IEEE Trans. Ind. Electron., Vol .51, No.3, pp. 526-536, Jun. 2004.

[8] D. R. Babu, B. Arundhati, and K. A. Mary, "Thrust ripples reduction for a vector controlled permanent magnet linear synchronous motor with IMC controller," International Journal of advanced Research in Electrical, Electronics \& Instrumentation Engineering, Vol. 1, No. 6, pp. 547-554, Dec. 2012.

[9] W. Q. Chu and Z. Q. Zhu "Investigation of torque ripples in permanent magnet synchronous machines with skewing," IEEE Trans. Magn., Vol. 49, No.3, pp. 1211-1220, Mar. 2013.

[10] S.-M. Jang, H.-I. Park, and J.-Y. Choi, K.-J. Choi, and S.-H. Lee, "Magnet pole shape design of permanent magnet machine for minimization of torque ripple based on electromagnetic field theory," IEEE Trans. Magn., Vol. 47, No. 10, pp. 3586-3589, Oct. 2011.

[11] W. Q. Chu and Z. Q. Zhu, "Investigation of torque ripples in permanent magnet synchronous machine with skewing," IEEE Trans. Magn., Vol. 49, No. 3, pp. 1211-1220, Mar. 2013

[12] B. Arundhati, K. Alice Mary, and M. Suryakalavathi, "Field oriented \& State Feedback control of a PMLSM in high Performance Motion System," International Journal of Engineering Research and Applications,Vol. 2, No. 2, pp. 734-737, Mar. 2012

[13] F. G. Jacek, J. Piech Zbigniew, and B. Tomcz, Linear Synchronous Motors: Transportation and Automation Systems, Electric Power Engineering Series, CRC press 2000.

[14] J. L. Semmlow and M. dekker, Bio Signal and Biomedical Image Processing, Inc. NewYork, 2004.

[15] S. Jayaraman, S. Esakkiraian, and T. Veerakumar, Digital Image Processing, Mc Hill Publication, 2012.

[16] H. Abu-Rub, A. Iqbal, and J. Guzinski, High Performance control of AC Drives with MATLAB Simulink Models, Wiley Publication, 2012.

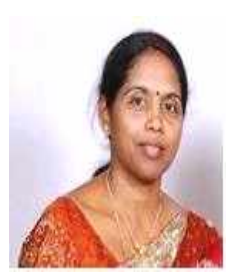

Arundhati Baratam was born in India. She received her B.S. degree from the College of Engineering, Sambalpur University, Sambalpur, India, in 1991, and her M.S. degree from Jawaharlal Nehru Technological University, Hyderabad, India, in 2005, where she is currently pursuing her Ph.D. She is presently working as an Associate Professor at the Vignan's Institute of Information Technology, Visakhapatna, India. Her current research interests include linear motors and control system applications for power electronics and machine drives.

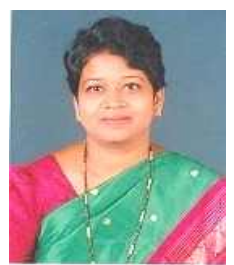

Alice Mary Karlapudy was born on April 24, 1959. She received her B.S. degree from the University BDTCE, Davanagere, India, in 1981, her M.S. degree from the Indian Institute of Technology Roorkee, Roorkee, India, in 1989, and her Ph.D. degree from the Indian Institute of Technology Kharaghpur, Kharaghpur, India, in 1998. She is presently working as a Professor and Principal of the Vignan's Institute of Information technology, Visakhapatnam, India. She has published 42 research papers, executed 7 government projects, and received many prestigious awards for her achievements in academic performance at the national level. She is presently guiding $5 \mathrm{Ph} . \mathrm{D}$. scholars. Her current research interests include control system applications for power electronics and machine drives.

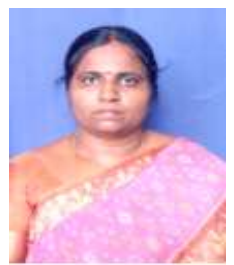

Suryakalavathi Munagala was born in Andhra Pradesh, India. She received her B.S. and M.S. degrees from Sri Venkateswara University, Tirupati, India, in 1988 and 1992, respectively, her $\mathrm{Ph} . \mathrm{D}$. degree from the Jawaharlal Nehru Technological University, Hyderabad, India, and her Post-Doctoral degree from Carnegie Mellon University, Pittsburg, PA, USA. She is presently working as a Professor in the College of Engineering, Jawaharlal Nehru Technological University Hyderabad (JNTUH), Hyderabad, India. She has published 20 research papers and is presently guiding $6 \mathrm{Ph} . \mathrm{D}$. scholars. She is specialized in power systems, high voltage engineering and control systems. Her current research interests include simulation studies on the transients of different power system equipment. 